\title{
Measured and predicted aerosol light scattering enhancement factors at the high alpine site Jungfraujoch
}

\author{
R. Fierz-Schmidhauser, P. Zieger, M. Gysel, L. Kammermann, P. F. DeCarlo, U. Baltensperger, and E. Weingartner \\ Laboratory of Atmospheric Chemistry, Paul Scherrer Institut, Villigen, Switzerland
}

Received: 24 July 2009 - Published in Atmos. Chem. Phys. Discuss.: 25 September 2009

Revised: 13 February 2010 - Accepted: 23 February 2010 - Published: 5 March 2010

\begin{abstract}
Ambient relative humidity (RH) determines the water content of atmospheric aerosol particles and thus has an important influence on the amount of visible light scattered by particles. The RH dependence of the particle light scattering coefficient $\left(\sigma_{\mathrm{sp}}\right)$ is therefore an important variable for climate forcing calculations. We used a humidification system for a nephelometer which allows for the measurement of $\sigma_{\mathrm{sp}}$ at a defined $\mathrm{RH}$ in the range of $20-95 \%$. In this paper we present measurements of light scattering enhancement factors $f(\mathrm{RH})=\sigma_{\mathrm{sp}}(\mathrm{RH}) / \sigma_{\mathrm{sp}}($ dry $)$ from a 1 -month campaign (May 2008) at the high alpine site Jungfraujoch (3580 m a.s.1.), Switzerland. Measurements at the Jungfraujoch are representative for the lower free troposphere above Central Europe. For this aerosol type hardly any information about the $f(\mathrm{RH})$ is available so far. At this site, $f(\mathrm{RH}=85 \%)$ varied between 1.2 and 3.3. Measured $f(\mathrm{RH})$ agreed well with $f(\mathrm{RH})$ calculated with Mie theory using measurements of the size distribution, chemical composition and hygroscopic diameter growth factors as input. Good $f(\mathrm{RH})$ predictions at $\mathrm{RH}<85 \%$ were also obtained with a simplified model, which uses the Ångström exponent of $\sigma_{\mathrm{sp}}(\mathrm{dry})$ as input. RH influences further intensive optical aerosol properties. The backscatter fraction decreased by about $30 \%$ from 0.128 to 0.089 , and the single scattering albedo increased on average by 0.05 at $85 \% \mathrm{RH}$ compared to dry conditions. These changes in $\sigma_{\mathrm{sp}}$, backscatter fraction and single scattering albedo have a distinct impact on the radiative forcing of the Jungfraujoch aerosol.
\end{abstract}

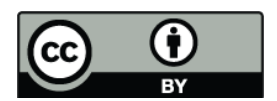

Correspondence to: E. Weingartner (ernest.weingartner@psi.ch)

\section{Introduction}

Atmospheric aerosols influence the Earth radiation budget by scattering and absorbing light. Further they act as cloud condensation nuclei and therefore influence the radiative properties and the lifetime of clouds. These two effects are called direct and indirect aerosol effect and are estimated to have an anthropogenic radiative forcing of -0.5 and $-0.7 \mathrm{Wm}^{-2}$, compared to $+2.66 \mathrm{Wm}^{-2}$ by greenhouse gases (IPCC, 2007). The anthropogenic aerosol forcing uncertainty is substantially larger than that of the greenhouse gases $\left(+0.8 /-1.5\right.$ vs. $\left.\pm 0.27 \mathrm{Wm}^{-2}\right)$ (IPCC, 2007). Therefore there is an urgent need to constrain this uncertainty.

To better quantify the direct effect it is important to understand how aerosol light scattering properties are influenced in the atmosphere. At high relative humidity (RH) liquid water comprises a major fraction of the atmospheric aerosol, and therefore the light scattering of aerosols expressed by the scattering coefficient $\left(\sigma_{\mathrm{sp}}\right)$ depends on $\mathrm{RH}$. The factor that quantifies this dependence is the light scattering enhancement factor $f(\mathrm{RH})=\sigma_{\mathrm{sp}}(\mathrm{RH}) / \sigma_{\mathrm{sp}}($ dry $)$. To ensure comparability between different $\sigma_{\mathrm{sp}}$ measurements at GAW (Global Atmosphere Watch) stations, the World Meteorological Organization (WMO) recommends measurements of $\sigma_{\mathrm{sp}}$ to be below 40\% RH (WMO/GAW, 2003), which is considered a dry measurement.

At a fixed RH, $f(\mathrm{RH})$ depends mainly on the dry particle size distribution and on the particles' hygroscopicity, which is determined by their chemical composition. For a constant chemical composition $f(\mathrm{RH})$ increases with decreasing particle size (see, e.g. Fierz-Schmidhauser et al., 2010).

Many studies have presented measurements of atmospheric aerosol light scattering enhancement factors $f(\mathrm{RH})$, e.g. for biomass burning aerosol (Kotchenruther and Hobbs, 1998; Kim et al., 2006), dust and pollution aerosol (Carrico et al., 2003; Kim et al., 2006), as well as for aerosols at rural

Published by Copernicus Publications on behalf of the European Geosciences Union. 
(Day and Malm, 2001), continental (Koloutsou-Vakakis et al., 2001; Sheridan et al., 2001) or urban (Yan et al., 2009) sites or close to the sea (Carrico et al., 1998, 2003; Wang et al., 2007). The highest $f(\mathrm{RH})$ were detected in Gosan, Korea, during measurements of pollution aerosols from China of 2.75 (at 85\% RH) and of volcanic aerosols during ACEAsia of 2.55 (at 82\% RH). During ACE-Asia, Carrico et al. (2003) measured a very low $f(\mathrm{RH})$ of 1.18 (at $82 \% \mathrm{RH}$ ) for dust dominated aerosol. In Brazil, biomass burning aerosol measurements revealed $f(\mathrm{RH})$ as low as 1.16 at $80 \% \mathrm{RH}$ (Kotchenruther and Hobbs, 1998).

The aerosol scattering coefficient $\sigma_{\mathrm{sp}}$ can be measured by an integrating nephelometer. To measure $\sigma_{\mathrm{sp}}$ at different RH, we built a humidification system for a commercial nephelometer (TSI Inc., model 3563) which allows for the measurement of $\sigma_{\mathrm{sp}}$ at a defined humidity below $95 \%$ RH (Fierz-Schmidhauser et al., 2010). The system is able to measure how hygroscopic properties and hysteresis effects of the atmospheric aerosol influence $\sigma_{\mathrm{sp}}$, and it can be continuously and remotely operated with very little maintenance. In May 2008 this humidified nephelometer measured in parallel with a dry nephelometer $(\mathrm{RH}<20 \%)$ at the high alpine site Jungfraujoch (JFJ). The Jungfraujoch is located at 3580 ma.s.l in the Swiss Alps and is designated a clean continental background station in Central Europe. JFJ is well suited for the study of background aerosols in climate research (Nyeki et al., 1998).

The scattering enhancement at higher RH influences the direct climate forcing by aerosol particles (Charlson et al., 1992; Schwartz, 1996). It is therefore desirable to be able to transform dry $\sigma_{\mathrm{sp}}$ into ambient $\sigma_{\mathrm{sp}}$ values. For this purpose we measured the size distribution and the chemical composition of the JFJ aerosol and performed a closure study using a model based on Mie theory, which can calculate the light scattering enhancement factor $f(\mathrm{RH})$ at different $\mathrm{RH}$. We also compared our model to another model developed by Nessler et al. (2005a).

In this paper we present model calculations of $f(\mathrm{RH})$ with different model assumptions (constant or variable chemical composition and size distribution) for the month of May 2008. The paper presents the sensitivity of $f(\mathrm{RH})$ on these two input parameters. The predicted $f(\mathrm{RH})$ results are compared to the measured $f(\mathrm{RH})$. Finally we present the impact of $\mathrm{RH}$ on other intensive aerosol properties and the radiative forcing.

\section{Experimental}

\subsection{Measurement site}

All data presented here were measured at the high alpine research station Jungfraujoch (JFJ, $\left.46^{\circ} 33^{\prime} \mathrm{N}, 7^{\circ} 59^{\prime} \mathrm{E}\right)$. The measurement campaign took place from 1 to 29 May 2008. The JFJ measurement site lies on an exposed mountain sad- dle on the north crest of the Bernese Alps, Switzerland, at $3580 \mathrm{~m}$ altitude. The JFJ is a Global Atmosphere Watch (GAW) site and aerosol measurements have been performed in this framework since 1995. It is also part of the Swiss National Monitoring Network for Air Pollution (NABEL) and the Federal Office of Meteorology and Climatology (MeteoSwiss). Baltensperger et al. (1997) and Collaud Coen et al. (2007) give more information on the JFJ site and the long-term aerosol measurements performed there. Due to its high elevation the JFJ resides predominantly in the free troposphere (FT) but can be affected by continental and regional pollution sources through vertical transport: During the warmer months injections of more polluted planetary boundary layer (PBL) air occur due to thermal convection. Consequently most extensive aerosol parameters undergo an annual cycle with maxima in the summer months and minima in the winter months (Baltensperger et al., 1991, 1997; Nyeki et al., 1998; Weingartner et al., 1999; Collaud Coen et al., 2007). A diurnal cycle due to mixing of convectively transported PBL aerosol with the air from the free troposphere is superimposed on this seasonal cycle, which often occurs during the spring and summer seasons. This diurnal cycle was clearly present during the first period of this campaign. Throughout the year the station is within clouds about one third of the time (Baltensperger et al., 1998).

\subsection{Instruments}

\subsubsection{Scattering coefficients at dry conditions and at high RH}

Since 1995 an integrating nephelometer (TSI Inc., model 3563 ) has measured the dry scattering coefficients $\sigma_{\mathrm{sp}}$ and dry backscattering coefficients $\sigma_{\text {bsp }}$ of total suspended particulate matter (TSP) at three wavelengths $(\lambda=450,550$ and $700 \mathrm{~nm}$ ) at the JFJ. During the campaign in May 2008 the RH in this nephelometer was always below $20 \% \mathrm{RH}$. No drying of the air is needed to achieve this low RH, since the temperature difference between the ambient atmosphere and the laboratory is typically more than $25^{\circ} \mathrm{C}$.

We built a novel humidification system for a second integrating nephelometer to measure the RH dependence of $\sigma_{\mathrm{sp}}$ and $\sigma_{\text {bsp }}$ at a defined RH in the range of $20-95 \%$ RH. The humidification system consists of a humidifier to rise the RH of the aerosol up to $95 \% \mathrm{RH}$, followed by a dryer, which dries to aerosol to the desired RH (Fierz-Schmidhauser et al., 2010). This system enables us to measure the hysteresis behavior of deliquescent aerosol particles. The light scattering enhancement factor $f(\mathrm{RH})$ is defined as the ratio of $\sigma_{\mathrm{sp}}$ at high and low RH:

$f(\mathrm{RH})=\frac{\sigma_{\mathrm{sp}}(\mathrm{RH})}{\sigma_{\mathrm{sp}}(\mathrm{RH}=\text { dry })}$.

The light backscattering enhancement factor, $f_{b}(\mathrm{RH})$, is defined similarly with $\sigma_{\text {bsp }}$. During the majority of the measurement period the humidified nephelometer measured at 
$85 \% \mathrm{RH}( \pm 10 \% \mathrm{RH})$. During four time periods, humidity cycles of the scattering enhancement, commonly referred to as humidograms, were determined. When both nephelometers measured at dry conditions $(\mathrm{RH}<40 \%)$ (3 May 20:00 LT (local time) to 5 May 10:00 LT) the two instruments agreed well with a slope of 1.03 , an intercept of $5 \times 10^{-7} \mathrm{~m}^{-1}$ and a correlation coefficient of $R^{2}=0.982$ (at $\lambda=550 \mathrm{~nm}$ ). $\sigma_{\mathrm{sp}}$ and $\sigma_{\mathrm{bsp}}$ were corrected for the truncation error according to Anderson and Ogren (1998). They used the Ångström exponent $\stackrel{\stackrel{a}{a}}{s}$ of the scattering coefficient, which is defined as:

$\sigma_{\mathrm{sp}}=c \lambda^{-\stackrel{\stackrel{\leftrightarrow}{a}_{s}}{s}}$.

The factor $c$ (turbidity coefficient) is related to the aerosol concentration and $\lambda$ is the wavelength of the light. Dividing $\sigma_{\text {bsp }}$ by $\sigma_{\text {sp }}$ results in the backscatter fraction $b$, which is the percentage of radiation that is scattered back at angles between $90^{\circ}$ and $180^{\circ} . b$ increases with decreasing particle size. If the sun is in the zenith, $b$ is equal to the upscatter fraction $\beta$. $\beta$ is the fraction of light that is scattered by a particle into the upward hemisphere relative to the local horizon, and consequently depends on the zenith angle and the particle size. In this study, $\beta$ is parameterized from the measured $b$ using the following equation for the global mean (Wiscome and Grams, 1976 in Sheridan et al., 1999):

$\beta=0.0817+1.8495 b-2.9682 b^{2}$.

Often, the actual RH in the nephelometer differed slightly from the target $\mathrm{RH}$ of $\mathrm{RH}_{\text {target }}=85 \%$. Several humidograms measured at different times could be well described with the following empirical relationship:

$f(\mathrm{RH})=\left(1+a \frac{\mathrm{RH}}{1-\mathrm{RH}}\right)^{\frac{7}{3}}$,

where $a$ is the only free parameter. This empirical relationship allows recalculation of $f(\mathrm{RH})$ to different $\mathrm{RH}$ values, assuming that it generally holds. Recalculated $f(\mathrm{RH})$ at $\mathrm{RH}_{\text {target }}=85 \%$ were determined in this way from $f(\mathrm{RH})$ measured at $75 \% \leq \mathrm{RH}_{\text {meas }} \leq 95 \%$ :

$$
\begin{aligned}
& f_{\text {recalc }}\left(\mathrm{RH}_{\text {target }}\right)=\left(1+a_{\text {meas }} \frac{\mathrm{RH}_{\text {target }}}{1-\mathrm{RH}_{\text {target }}}\right)^{\frac{7}{3}} \\
& =\left(1+\left[f_{\text {meas }}^{\frac{3}{7}}-1\right] \frac{1-\mathrm{RH}_{\text {meas }}}{\mathrm{RH}_{\text {meas }}} \frac{\mathrm{RH}_{\text {target }}}{1-\mathrm{RH}_{\text {target }}}\right)^{\frac{7}{3}} .
\end{aligned}
$$

\subsubsection{Particle number size distributions}

A scanning mobility particle sizer (SMPS) measured the dry particle size distribution in the particle mobility diameter range $12 \mathrm{~nm}<D_{p}<562 \mathrm{~nm}$. This instrument consists of a differential mobility analyzer (DMA) followed by a condensation particle counter (CPC, TSI Inc., model 3772). The SMPS had a closed loop configuration for the sheath and excess air. The volumetric sheath air flow rate was held constant at $5 \mathrm{lpm}$ (liters per minute) by means of a mass flow controller combined with temperature and pressure sensors. The sample flow rate was $1 \mathrm{lpm}$. In addition, an optical particle counter (OPC, Grimm Dustmonitor 1.108) measured the dry size distribution of the larger particles in the optical diameter range $0.3 \mu \mathrm{m}<D_{p}<25 \mu \mathrm{m}$. In the OPC the individual particles are classified according to their light scattering behavior, which depends on the particle size, morphology and refractive index. The comparison of the size distribution spectra of the OPC and the SMPS showed that the OPC diameters need to be slightly shifted (multiplication of the diameter by 1.12 on average) to larger sizes to get good agreement. A similar disagreement was found in a different study at the JFJ site by Cozic et al. (2008).

The combined SMPS and OPC data were used as input for the Mie calculation. All diameter corrected data from the OPC were taken, whereas the SMPS data were just used up to $D_{p}=340 \mathrm{~nm}$, to avoid the influence of doubly and triply charged particles for larger diameters. A comparison of the integrated size distribution of the SMPS and OPC to a second CPC, measuring the total number concentration, showed that the SMPS measured $\sim 20 \%$ less than the CPC, if large nucleation events (with high concentrations of particles with $D_{p}<30 \mathrm{~nm}$ ) were excluded for the comparison. The corrected and combined SMPS and OPC data were used as an input for the model calculations (see Sect. 2.3).

\subsubsection{Hygroscopic properties}

A hygroscopicity tandem differential mobility particle sizer (H-TDMA), based on the instrument presented by Weingartner et al. (2002), was operated to measure the hygroscopic diameter growth factors $(g)$, defined as the diameter ratio of high RH and dry conditions. The H-TDMA functions as follows: Particles are dried to $\mathrm{RH}<10 \%$ and brought to charge equilibrium before a first DMA is used to select a dry monodisperse size of the polydisperse aerosol. These particles with a well defined dry diameter then pass through a humidifier before the resulting equilibrium diameters are measured using a second DMA operated at a well defined high RH (typically 90\%). The mean growth factor $g$, measured at $\mathrm{RH}=90 \% \pm 3 \%$, was obtained from the raw measurement distributions using the TDMAinv inversion algorithm (Gysel et al., 2009). Dry diameters measured in this study were 35 , $50,75,110,165$ and $265 \mathrm{~nm}$.

\subsubsection{Chemical composition}

An Aerodyne High Resolution Time-of-Flight Aerosol Mass Spectrometer (AMS) measured the size resolved aerosol chemical composition of non-refractory submicron aerosol particles. The instrument has been characterized in detail elsewhere (DeCarlo et al., 2006; Canagaratna et al., 2007). Briefly, aerosol is introduced into the instrument via an aerodynamic lens which focuses the aerosol into a tight beam. The particle beam impacts on an inverted conical tungsten 
Table 1. Microphysical properties of selected aerosol compounds used for the model predictions. The imaginary part of the complex refractive index $n$ was omitted for all components except for black carbon (BC). All values are interpolated to the nephelometer wavelengths. Mean concentrations (and standard deviations) are for the entire measurement period.

\begin{tabular}{|c|c|c|c|c|c|c|c|}
\hline & $\lambda$ & Organics & $\mathrm{NH}_{4} \mathrm{NO}_{3}$ & $\left(\mathrm{NH}_{4}\right)_{2} \mathrm{SO}_{4}$ & $\mathrm{NH}_{4} \mathrm{HSO}_{4}$ & $\mathrm{H}_{2} \mathrm{SO}_{4}$ & $\mathrm{BC}$ \\
\hline \multirow{3}{*}{$n_{i}$} & $450 \mathrm{~nm}$ & & $1.559^{b}$ & $1.536^{b}$ & \multirow{3}{*}{$1.473^{\mathrm{c}, \mathrm{h}}$} & $1.438^{\mathrm{d}}$ & $1.75+0.46 \mathrm{i}^{\mathrm{e}}$ \\
\hline & $550 \mathrm{~nm}$ & $1.48^{\mathrm{a}, \mathrm{h}}$ & $1.556^{\mathrm{b}}$ & $1.530^{\mathrm{b}}$ & & $1.434^{\mathrm{d}}$ & $1.75+0.44 \mathrm{i}^{\mathrm{e}}$ \\
\hline & $700 \mathrm{~nm}$ & & $1.553^{b}$ & $1.524^{b}$ & & $1.432^{d}$ & $1.75+0.43 \mathrm{i}^{\mathrm{e}}$ \\
\hline \multicolumn{2}{|c|}{$\rho_{i}\left(\mathrm{~g} / \mathrm{cm}^{3}\right)$} & $1.4^{\mathrm{f}}$ & $1.72^{\mathrm{g}}$ & $1.77^{\mathrm{g}}$ & $1.78^{\mathrm{g}}$ & $1.83^{\mathrm{g}}$ & $1.7^{\mathrm{a}}$ \\
\hline \multicolumn{2}{|c|}{$\begin{array}{l}\text { mean conc. } \\
\left(\mu \mathrm{g} / \mathrm{m}^{3}\right)(\mathrm{std})\end{array}$} & $\begin{array}{l}0.703 \\
(0.808)\end{array}$ & $\begin{array}{l}0.370 \\
(0.638)\end{array}$ & $\begin{array}{l}0.450 \\
(0.611)\end{array}$ & $\begin{array}{l}0.097 \\
(0.111)\end{array}$ & $\begin{array}{l}0.013 \\
(0.027)\end{array}$ & $\begin{array}{l}0.057 \\
(0.054)\end{array}$ \\
\hline
\end{tabular}

a Nessler et al. (2005a); ${ }^{b}$ Software from Andrew Lacis (from http://gacp.giss.nasa.gov/data_sets/, last visited on 19 May 2009) based on Toon et al. (1976); Gosse et al. (1997); Tang (1996); ${ }^{\mathrm{c}}$ Li et al. (2001); ${ }^{\mathrm{d}}$ Palmer and Williams (1975); ${ }^{\mathrm{e}}$ Hess et al. (1998); ${ }^{\mathrm{f}}$ Alfarra et al. (2006); Dinar et al. (2006); ${ }^{\mathrm{g}}$ Lide (2008); ${ }^{\mathrm{h}}$ No wavelength dependence assumed.

vaporizer at $600^{\circ} \mathrm{C}$, where the non-refractory components are flash vaporized. The resulting gas phase plume is ionized by electron ionization at $70 \mathrm{eV}$. A high mass resolution mass spectrometer (H-TOF, Tofwerk AG, Thun, Switzerland) produces mass spectra which are processed using custom software to give mass concentrations of non-refractory species. At the JFJ the AMS measured with a collection efficiency of 1 . This collection efficiency was determined based on intercomparisons of the AMS with both SMPS and dry nephelometer measurements at JFJ. This particular instrument has been deployed at several other locations where intercomparisons with other instruments including other AMS instruments consistently report a collection efficiency of 1 for ambient aerosol. Table 1 lists the mean concentrations measured at the JFJ.

\subsubsection{Light absorption coefficient}

The aethalometer (AE-31, Magee Scientific) has measured light absorption coefficients $\left(\sigma_{\mathrm{ap}}\right)$ of TSP at seven wavelengths $(\lambda=370,470,520,590,660,880,950 \mathrm{~nm})$ at the JFJ since 2001. According to Weingartner et al. (2003) $\sigma_{\text {ap }}$ was calculated with:

$\sigma_{\mathrm{ap}}=\frac{A}{Q} \frac{\Delta \mathrm{ATN}}{\Delta t} \frac{1}{C R(\mathrm{ATN})}$,

where $A$ is the filter spot area, $Q$ the volumetric flow rate and $\triangle \mathrm{ATN}$ the change in attenuation during the time interval $\Delta t$. $C$ has a value of 2.81 for the JFJ and is a wavelength independent empirical correction factor (Collaud Coen et al., 2009). It corrects for multiple reflections of the light beam at the filter fibers, which enhances the optical path in the filter of the aethalometer. $R$ corrects for the loading dependent shadowing effect. $R=1$ is used for the aged aerosol at the JFJ (Weingartner et al., 2003).
The black carbon (BC) concentration was calculated from $\sigma_{\text {ap }}$ at $880 \mathrm{~nm}$ using an optical absorption cross-section of the manufacturer $\left(16.6 / \mathrm{C} \mathrm{m}^{2} / \mathrm{g}=5.91 \mathrm{~m}^{2} / \mathrm{g}\right)$. It is a common practice to use this wavelength for the determination of equivalent $\mathrm{BC}$ concentrations since smaller wavelengths may have stronger contributions by other aerosol components (such as organic matter or mineral dust).

The aerosol single scattering albedo $\omega_{0}$ describes the relative contribution of scattering to the total light extinction:

$\omega_{0}=\frac{\sigma_{\mathrm{sp}}}{\sigma_{\mathrm{sp}}+\sigma_{\mathrm{ap}}}$.

Since $\omega_{0}$ is wavelength dependent $\sigma_{\mathrm{sp}}$ and $\sigma_{\text {ap }}$ need to be at the same wavelength. Therefore we transformed $\sigma_{\mathrm{ap}}$ measured by the aethalometer to the nephelometer wavelengths 450,550 and $700 \mathrm{~nm}$ by using the measured Ångström exponent for the absorption $\stackrel{\circ}{a}_{a}$ (in analogy to Eq. 2).

\subsection{Mie calculations to predict $f(\mathbf{R H})$}

\subsubsection{Using measured physical and chemical properties}

We predicted $f(\mathrm{RH})$ with a model based on Mie theory (Mie, 1908) where the core Mie routine is based on the code of Bohren and Huffmann (2004). The particles are assumed to be spherical and homogenously internally mixed. As input the number size distribution and the complex refractive index $n$ of the measured aerosol are needed. The SMPS and OPC measured number size distribution; both were combined at $340 \mathrm{~nm}$ (see Sect. 2.2.2). The complex refractive index was calculated using the chemical composition measurements of the AMS and the aethalometer. A time resolved mean refractive index was then determined by a volume fraction averaging:

$n(\lambda)=\sum \frac{m f_{i}}{\rho_{i}} n_{i}(\lambda)$, 
where $m f_{i}$ is the mass fraction, $\rho_{i}$ is the density and $n_{i}(\lambda)$ is the wavelength dependent complex refractive index of the compound $i$. We took the values for $n_{i}$ and $\rho_{i}$ as listed in Table 1.

Hygroscopic growth was accounted for in two alternative ways: either by directly using the size resolved H-TDMA measurements of diameter growth factors or by calculating the hygroscopic growth factor from AMS and aethalometer measurements. The H-TDMA growth factors $g(\mathrm{RH}=90 \%)$ were extrapolated to different RH using Eq. (3) from Gysel et al. (2009), which uses the $\kappa$-model introduced by Petters and Kreidenweis (2007). For the wet refractive index a volume weighting between the refractive indices of water and the according dry aerosol was chosen (Hale and Querry, 1973).

The AMS plus aethalometer measurements can also be used to calculate the hygroscopic growth factor. For this, we used the individual $g$ values for the retrieved salts and acids that were derived from Topping et al. (2005). For the organic component, we used a growth factor of 1.2 at $\mathrm{RH}=85 \%$, which is representative for aged organic aerosol at the JFJ (Sjogren et al., 2008). The BC is believed to be insoluble, i.e. $g=1$. An mean growth factor is then calculated from the growth factors of the individual components of the aerosol and their respective volume fractions with the ZSR relation (Stokes and Robinson, 1966).

\subsubsection{Using the Ångström exponent as only directly measured input}

Nessler et al. (2005a) proposed a specific algorithm for the JFJ site to adapt dry nephelometer measurements to ambient conditions. They used a coated sphere model also based on Mie theory to calculate $f(\mathrm{RH})$. The fine mode was modeled assuming an insoluble core and a homogeneous soluble coating, which absorbs an increasing amount of water with increasing RH. The relative amounts of insoluble and soluble material in the fine mode were derived from experimental chemical composition and hygroscopic growth data. To get a representative range of the JFJ size distributions, Nessler et al. (2005a) combined 15 months of averaged SMPS and OPC data and fitted them with the sum of three log-normal distributions. By varying the geometric standard deviations, median diameters, and coarse mode concentrations within the $\pm 15 \%$ interval of the fitted parameters, they obtained size distributions considered representative for the JFJ aerosol. The coarse mode is considered to be insoluble (no hygroscopic growth), as it is mainly mineral dust which is detected in this size range. The Ångström exponent $\stackrel{\circ}{a}_{s}$ (see Eq. 2), is used as a proxy for the relative contributions of fine and coarse mode particles, and is beside the RH in the nephelometer the only input parameter required to calculate $f(\mathrm{RH})$. The parameterization is given for a separate summer and a winter case and is valid in the range of $-0.25<\check{a}_{s}<2.75$ and $0 \%<\mathrm{RH}<90 \%$. Our measurement period lies within the proposed summer case scenario.

\section{Results and discussion}

First we give an overview of the measured light scattering enhancement factors $f(\mathrm{RH})$ in combination with other measurements, then we demonstrate how $f(\mathrm{RH})$ can be predicted and finally we investigate the impact of $\mathrm{RH}$ on further climate relevant intensive properties.

\subsection{Measured $f(\mathrm{RH})$}

\subsubsection{Overview}

Figure 1 shows an overview of the measured scattering coefficient $\sigma_{\mathrm{sp}}$ and the light scattering enhancement factor $f(\mathrm{RH})$ at $85 \%$ RH of the campaign in May 2008 at the JFJ. Every data point represents hourly averaged data. All time scales are Central European Summer Time $(\mathrm{CEST}=\mathrm{UTC}+2 \mathrm{~h})$. Figure 1a displays the scattering coefficient $\sigma_{\mathrm{sp}}$ at $550 \mathrm{~nm}$ wavelength. The nephelometer measured hourly averaged $\sigma_{\mathrm{sp}}$ values between 0 and $1.1 \times 10^{-4} \mathrm{~m}^{-1}$. The highest scattering signal occurred on 28 May, during a strong Saharan dust event (SDE). The mean $\sigma_{\mathrm{sp}}$ of the measurement campaign is shown in Table 2 (without SDE and for SDE only). $\sigma_{\mathrm{sp}}$ shows higher values during the first half of the measurement campaign (1 to 16 May) than during the second half (16 to 26 May), until the SDE started. We will treat the time period of the SDE separately (Sect. 3.1.2). We explain the low scattering coefficients of the second half of the measurement campaign by high cloud coverage and precipitation. $\sigma_{\mathrm{sp}}$ values below $10^{-6} \mathrm{~m}^{-1}$ for hourly means were included in the calculation of means of $\sigma_{\mathrm{sp}}$ but not for further data analysis. We highlighted these data points in light green in the curve of $\sigma_{\mathrm{sp}}$ in Fig. 1. For the prediction of $f(\mathrm{RH})$ (see Sect. 3.2) $\sigma_{\mathrm{sp}}$ values below $5 \times 10^{-6} \mathrm{~m}^{-1}$ were not used, and are shown in grey in Fig. 1a.

Figure $1 \mathrm{~b}$ presents light scattering enhancement factors $f(\mathrm{RH}=85 \%)$ at 450,550 and $700 \mathrm{~nm}$ wavelength. These data points originate from scattering coefficients that were measured by the humidified nephelometer at a $\mathrm{RH}$ between 75 and $95 \%$ and were recalculated to $\mathrm{RH}=85 \%$ with Eq. (5). During most of the time the instrument measured at $85 \% \mathrm{RH}( \pm 10 \% \mathrm{RH})$, and $f(\mathrm{RH}=85 \%)$ varied between 1.2 and 3.3 (mean shown in Table 2). Daily averaged values of $f(\mathrm{RH}=85 \%)$ were between 1.65 and 2.82 , with low values $(<2)$ on 6, 18 and 26 May and values above 2.7 on 10, 12 and 13 May. A back trajectory analysis (FLEXTRA) for the days with $f(\mathrm{RH}=85 \%)>2.7$ showed that the air masses reaching JFJ often did not pass below 1000 ma.s.l. within the last 7 days. The few times they did it nonetheless was over the Atlantic Ocean. On these days we measured inorganic mass fractions higher than 0.57 , largest particle mean diameters and high hygroscopic growth factors $(g(\mathrm{RH}=90 \%)>1.55$ for particles with a dry diameter of $265 \mathrm{~nm}$ ). The air masses that reached the JFJ on days with low $f(\mathrm{RH})$ either passed at less than $1000 \mathrm{~m}$ a.s.l. in eastern Europe (6 May), in southwestern 
Table 2. Scattering coefficient $\sigma_{\mathrm{sp}}$, light scattering enhancement factor $f(\mathrm{RH}=85 \%)$, light backscattering enhancement factor $f_{b}(\mathrm{RH}=85 \%)$, backscatter fraction $b$, single scattering albedo $\omega_{0}$, Ångström exponent $\stackrel{\circ}{a}_{s}$ and hygroscopic growth factor of $265 \mathrm{~nm}$ dry particles $g(D=265 \mathrm{~nm}, \mathrm{RH}=90 \%)$ averaged over the whole campaign excluding Saharan dust event (SDE) and averaged exclusively during the SDE.

\begin{tabular}{llccc}
\hline & \multicolumn{4}{c}{ Campaign average } \\
& \multicolumn{2}{c}{ Excluding SDE } & Exclusively SDE \\
& $<20 \% \mathrm{RH}$ & $85 \% \mathrm{RH}$ & $<20 \% \mathrm{RH}$ & $85 \% \mathrm{RH}$ \\
\hline$\sigma_{\mathrm{sp}}(550 \mathrm{~nm})\left[\mathrm{m}^{-1}\right]$ & $1.19 \times 10^{-5}$ & & $2.05 \times 10^{-5}$ \\
$f(\mathrm{RH}=85 \%)$ & & 2.23 & & 1.72 \\
$f_{b}(\mathrm{RH}=85 \%)$ & & 1.60 & & 1.54 \\
$b$ & 0.128 & 0.089 & 0.122 & 0.101 \\
$\omega_{0}$ & 0.907 & 0.954 & 0.930 & 0.960 \\
$\stackrel{\circ}{a}_{S}$ & 1.787 & 0.839 & 1.671 & 1.111 \\
$g(D=265 \mathrm{~nm}, \mathrm{RH}=90 \%)$ & \multicolumn{3}{c}{1.522} & \multicolumn{3}{c}{ n.a. } \\
\hline
\end{tabular}

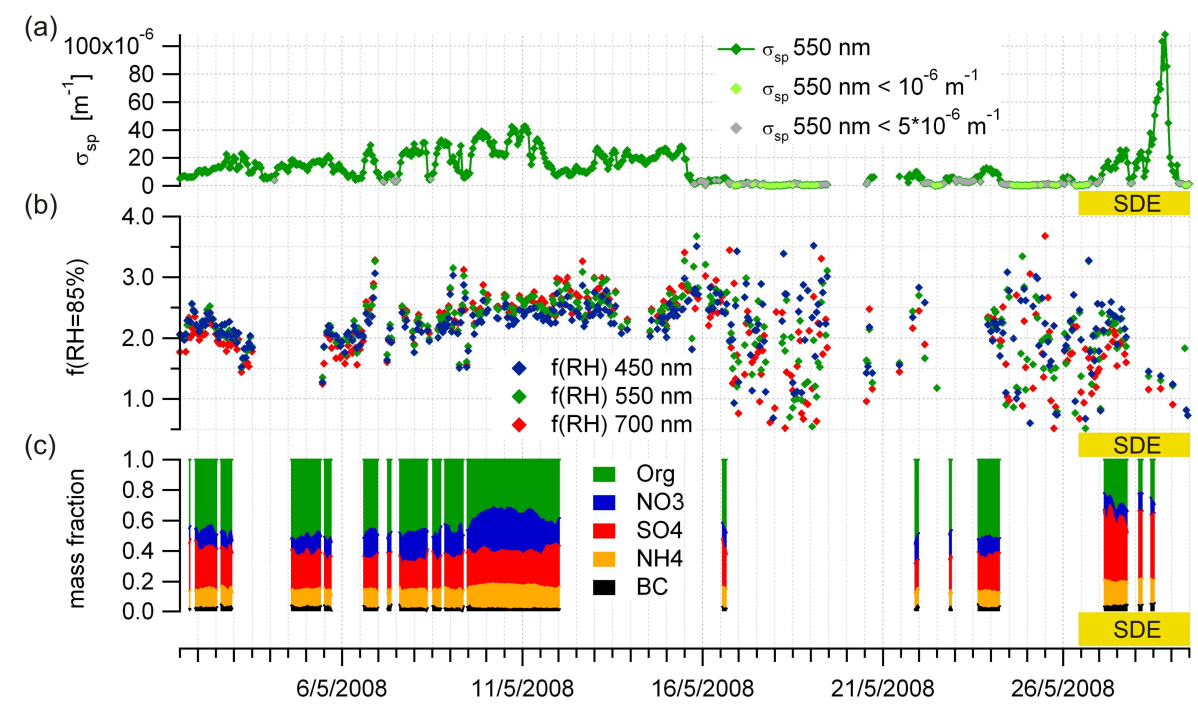

Fig. 1. Time series of the scattering coefficient $\left(\sigma_{\mathrm{sp}}\right)$ at $550 \mathrm{~nm}$ wavelength (a), measured $f(\mathrm{RH})$ recalculated to $\mathrm{RH}=85 \%$ of three distinct wavelengths (b) and the mass fractions of organics, nitrate, sulfate, ammonium and black carbon (c). SDE indicates the time period, when a Saharan dust event was present. The scattering coefficients shown in light green are below $10^{-6} \mathrm{~m}^{-1}$, those shown in grey are below $5 \times 10^{-6} \mathrm{~m}^{-1}$.

and mideastern Europe (19 May), or in northern Africa (26 May). By passing over populated areas the air probably picked up more organic matter which results in a decrease of $f(\mathrm{RH})$. This hypothesis can be only confirmed for one day, because of gaps in the AMS measurements on the other days. On 6 May the mean mass fraction of the inorganic compounds was 0.43 .

In the beginning of the measurement campaign (13 May) the $f(\mathrm{RH}=85 \%, \lambda=700 \mathrm{~nm})$ was lower compared to $f(\mathrm{RH}=85 \%, \lambda=450 \mathrm{~nm})$ while it was larger in the middle of the measurement campaign (11-14 May). This spectral behavior is explainable by a smaller coarse mode fraction and generally smaller particles in the latter case.

\subsubsection{Saharan dust event (SDE)}

In the end of the measurement campaign a strong Saharan dust event took place (26 May 12:00 LT to 29 May 12:00 LT). During a SDE the aerosol exhibits properties significantly different from the background conditions (Schwikowski et al., 1995; Collaud Coen et al., 2004). Such a SDE event significantly increases the coarse mode mass concentration but it also has an important influence on the accumulation mode. The H-TDMA was not running at this time, but typically shows an external mixture at $250 \mathrm{~nm}$ when there is significant influence of dust particles, which was also reported by Sjogren et al. (2008). The $f(\mathrm{RH}=85 \%)$ during the most intensive time of the was the lowest during 
the whole measurement campaign, with an hourly averaged value of 1.2. Similarly, Carrico et al. (2003) measured in the ACE-Asia campaign during the most dust-dominated period a $f(\mathrm{RH})$ at $82 \%$ of 1.18 . Our findings also agree with the ones of Li-Jones et al. (1998), who investigated the $f(\mathrm{RH})$ of long-range transported Saharan dust.

\subsubsection{Diurnal variations}

At the JFJ extensive aerosol properties undergo diurnal variations, which are strongest in spring and summer (Baltensperger et al., 1997; Lugauer et al., 1998; Weingartner et al., 1999). In May 2008 (without SDE) $\sigma_{\mathrm{sp}}$ also varied throughout the day with a maximum in the late afternoon to early evening and a minimum before noon. The maximum was on average 1.5 times higher than the minimum $\left(9.5 \times 10^{-6} \mathrm{~m}^{-1}\right)$. The intensive parameter $f(\mathrm{RH}=85 \%) \mathrm{did}$ not experience a clear diurnal pattern in the same time period. A further analysis showed that here $\sigma_{\mathrm{sp}}$ increased due to an increase in the aerosol load rather than a change in the chemical composition or the size distribution. The time period of 6 to 11 May had long sunshine duration, favoring thermal convection. During this period the diurnal pattern of $\sigma_{\mathrm{sp}}$ was much more distinct, with the maximum being more than three times higher than the minimum $\left(8.5 \times 10^{-6} \mathrm{~m}^{-1}\right)$. In this period, averaged $f(\mathrm{RH})$ values did indeed exhibit a diurnal variation, with the maximum roughly at the same time as $\sigma_{\mathrm{sp}}$, suggesting that the chemical composition (or the size distribution) of the aerosol from the PBL was different from the one in the free troposphere. It can, however, be expected that also the reverse diurnal variation is possible, with $f(\mathrm{RH})$ being minimal when $\sigma_{\mathrm{sp}}$ shows its maximum.

\subsubsection{Humidograms}

During four time periods the $\mathrm{RH}$ in the humidified nephelometer was cycled between 20 and $95 \% \mathrm{RH}$ thus providing $f(\mathrm{RH})$ over a wide range of $\mathrm{RH}$, also commonly referred to as humidograms. No distinct efflorescence or deliquescence effects were seen, which is in line with previous $\mathrm{H}$ TDMA humidograms recorded at this site (Weingartner et al., 2002; Sjogren et al., 2008). Figure 2 presents $f(\mathrm{RH})$ (top) and $f_{b}(\mathrm{RH})$ (bottom) at $550 \mathrm{~nm}$ wavelength of four measured humidograms. Each humidogram consists in maximum of two RH cycles, with 10-min means at each RH. The humidograms plotted with the diamond markers $(6 / 7,13$ and 14 May) all have a similar shape and similar magnitude of $f(\mathrm{RH})$. On 6 May there is much more variability in the $f(\mathrm{RH})$ data compared to 13 and 14 May, also seen in Fig. 1 for $\sigma_{\mathrm{sp}}$ data, which is attributed to a lower signal to noise ratio due to a lower aerosol loading. The humidogram in yellow was measured when the Saharan dust event was strongest. The aerosol grows very little with increasing $\mathrm{RH}$, resulting in an $f(\mathrm{RH})$ at $85 \%$ of $\sim 1.2$.
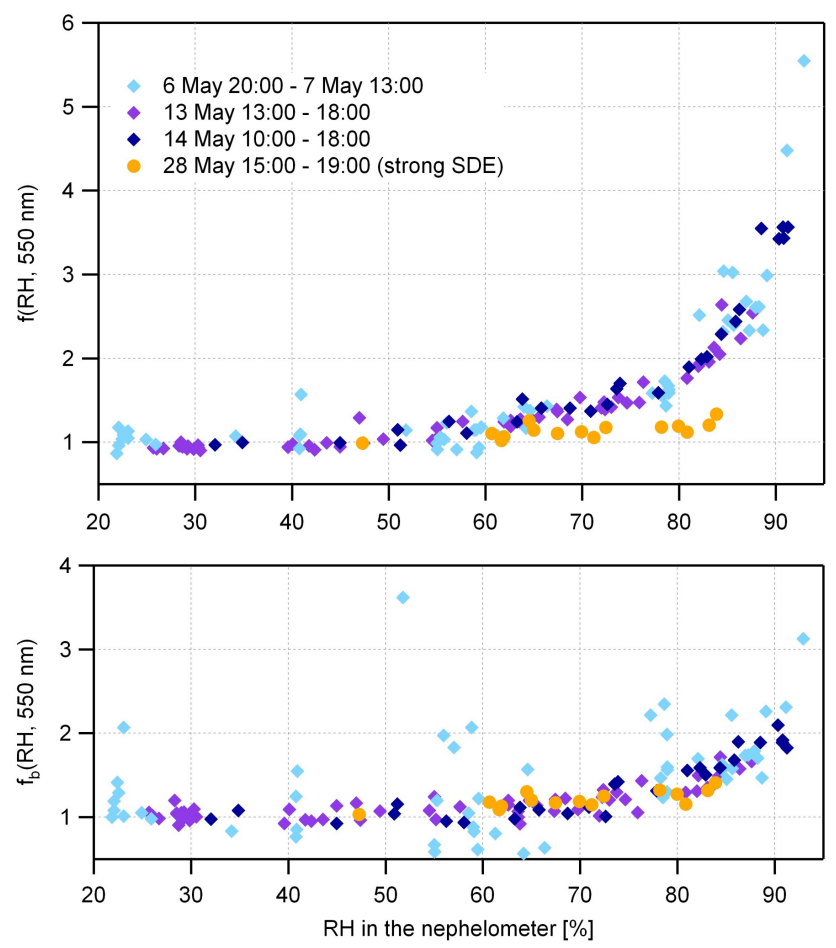

Fig. 2. Light scattering enhancement factor $f(\mathrm{RH})$ (top) and light backscattering enhancement factor $f_{b}(\mathrm{RH})$ (bottom) at $550 \mathrm{~nm}$ wavelength vs. RH at four different time periods when the RH in the humidified nephelometer was cycled (max. 2 cycles per period).

There is no significant difference of $f_{b}(\mathrm{RH})$ between the SDE and the other days. Smaller particles scatter relatively more light in the backward direction, so when water is added the $f_{b}(\mathrm{RH})$ is much smaller than the $f(\mathrm{RH})$. During a SDE the particles are larger and grow less and therefore the $f_{b}(\mathrm{RH})$ increases by about the same factor as without a SDE.

\subsection{Prediction of $f(\mathbf{R H})$}

\subsubsection{RH dependence}

The scattering coefficients were calculated for each measurement point of the humidified nephelometer. The calculated dry and humid scattering coefficients were $\sim 20 \%$ below the measured ones (with a correlation coefficient $R^{2}=0.97$ at $550 \mathrm{~nm}$ wavelength), which we attribute to a systematic bias in the measured model input parameters. The scattering coefficient at dry conditions depends on the aerosol chemical composition (via the refractive index), on the shape of the aerosol size distribution (or mean size) and on the aerosol concentration. The influence of the refractive index is not large enough to account for the encountered discrepancy of $20 \%$. It is speculated that this discrepancy is manly caused by a small systematic error in the measurement of the size distribution (i.e., either in the determination of the diameter or number concentration, or a combination of both). Since 

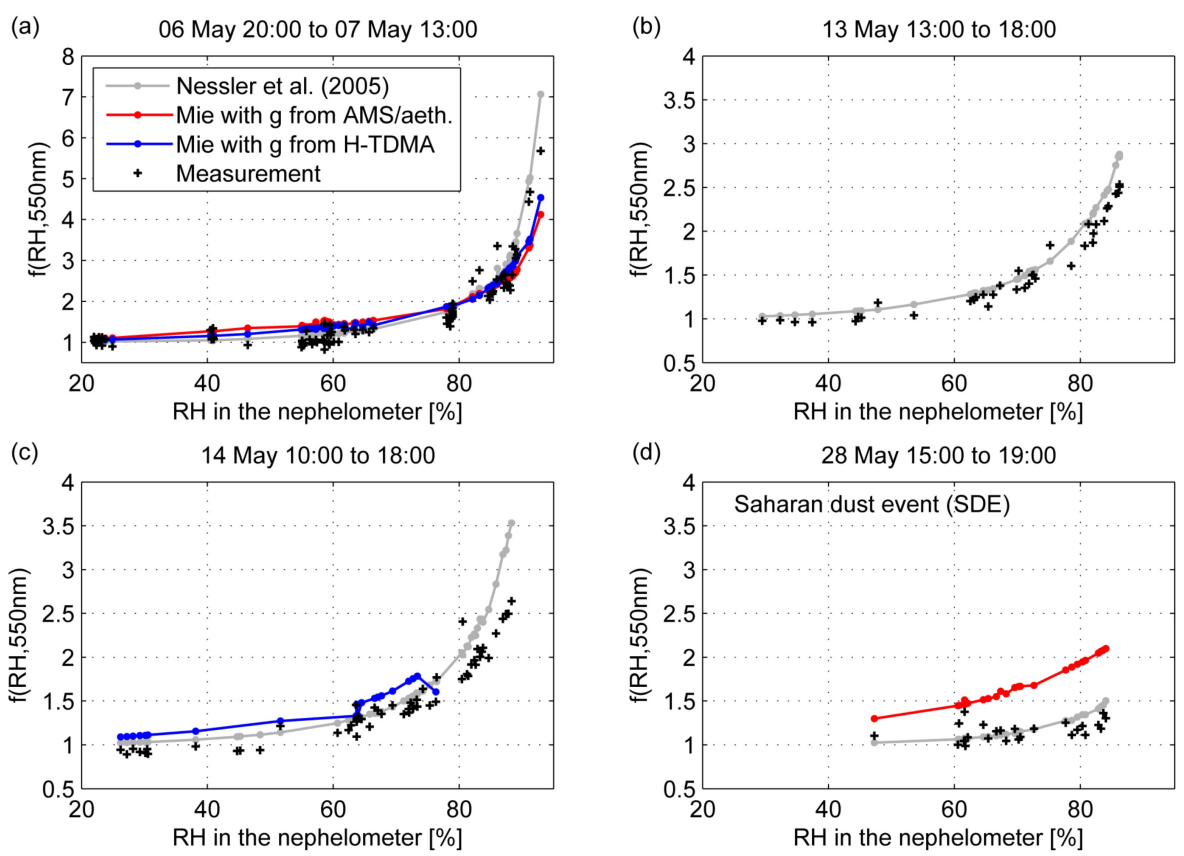

Fig. 3. Humidograms showing measured (black symbols) and predicted $f(\mathrm{RH})$ vs. RH in the nephelometer for four example days in May 2008. The grey lines are calculated according to the approach by Nessler et al. (2005a). The red and blue lines are calculated with Mie theory using a combination of size distribution, chemical composition and hygroscopicity data. The latter are inferred either by the H-TDMA (blue lines) or the AMS/aethalometer data (red points). (d) shows a humidogram from the time period of the Saharan dust event (SDE). For 13 and 28 May, no H-TDMA data was available, whereas no AMS/aethalometer data was available on 13 and 14 May.

$f(\mathrm{RH})$ is not sensitive to the total number concentration and only slightly sensitive to the aerosol size distribution shape (see Sect. 3.2.2), we can neglect the constant difference in the absolute values.

The predicted $f(\mathrm{RH})$ depends on the aerosol size distribution, on the chemical composition of the aerosol and on the RH in the nephelometer. The chemical composition is used to determine the refractive index and the hygroscopic growth factor $g . g$ can be calculated from measurements of the chemical composition by the AMS and the aethalometer or direct measurements with the H-TDMA.

Figure 3 presents the same humidograms as in Fig. 2 (top) (6/7, 13, 14 and 28 May), along with predicted humidograms. The black points in all four panels represent the measured $f(\mathrm{RH})$. The colored points show the $f(\mathrm{RH})$ predicted by different model approaches (see Sect. 2.3). The red points denote $f(\mathrm{RH})$ predictions based on $g$ values calculated from the AMS and aethalometer data, whereas the blue lines show $f(\mathrm{RH})$ predictions from the $g$ values obtained by the H-TDMA. The grey points were calculated using the approach of Nessler et al. (2005a).

On 6/7 May (Fig. 3a) all instruments needed for these predictions were running. All model approaches agree well with the measurements and are similar up to $80 \%$ RH. Above $80 \%$ RH, the algorithm by Nessler et al. (2005a) overestimates $f(\mathrm{RH})$, whereas the Mie calcula- tions based on $g$ values derived either from H-TDMA or AMS/aethalometer measurements underestimate $f(\mathrm{RH})$. Neither AMS/aethalometer nor H-TDMA data are available on 13 May and only partly on 14 May (Fig. 3b, c). Predictions available for these days agree quite well with measurements, with the limitation that the algorithm by Nessler et al. (2005a) overestimates $f(\mathrm{RH})$ above $85 \%$ RH. On 28 May (Fig. 3d), when the SDE was present, the Mie calculation with $g$ from the AMS/aethalometer results in a $f(\mathrm{RH})$ that is quite different from the measured one (no H-TDMA data were available on this day). This is reasonable since Saharan dust contains a large fraction of refractory material (Schwikowski et al., 1995; Collaud Coen et al., 2004; Cozic et al., 2008) which is not detected by the AMS. In addition, the AMS does not measure super-micrometer particles, which are much more abundant during a SDE. The Nessler algorithm predicts $f(\mathrm{RH})$ quite well during the SDE. As explained above, the only input variable is the Ångström exponent (values in Table 2), which is a proxy for the detected size distribution. At low values $\left(\stackrel{a}{s}_{s}<1\right)$ the aerosol size distribution is dominated by the coarse mode which exhibits much less hygroscopic growth than the accumulation mode.

Figure $4 \mathrm{a}$ and $\mathrm{b}$ present the sensitivity of the model predictions to the source of the hygroscopic growth data. The x-axes always show the measured $f(\mathrm{RH})$, whereas the $\mathrm{y}$ axes display the predicted $f(\mathrm{RH})$, with $g$ obtained from the 
(a)

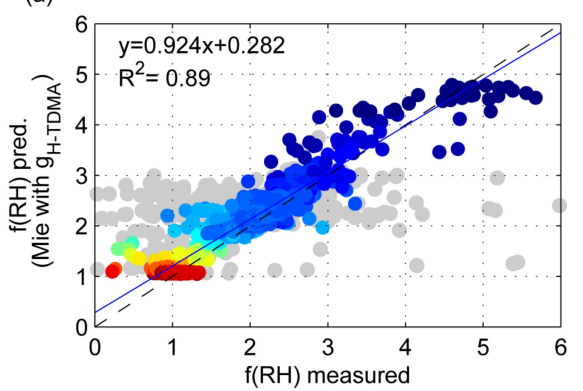

(c)

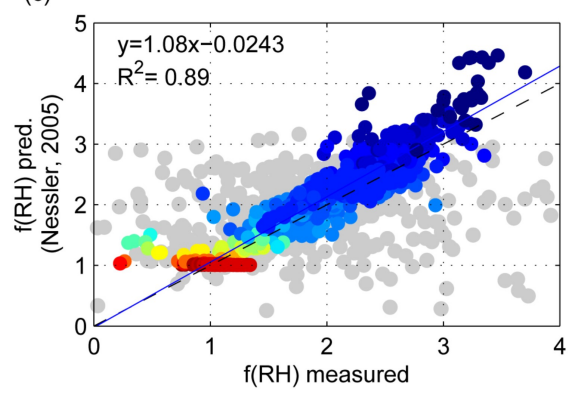

(b)

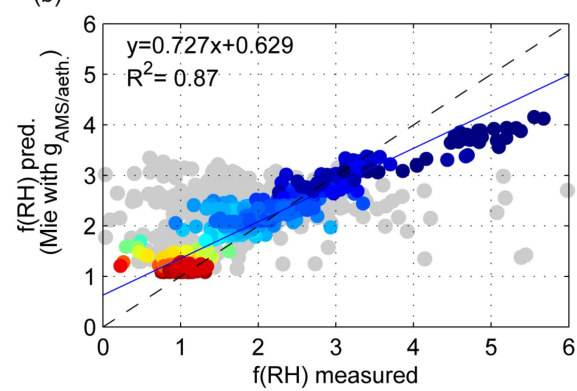

(d)

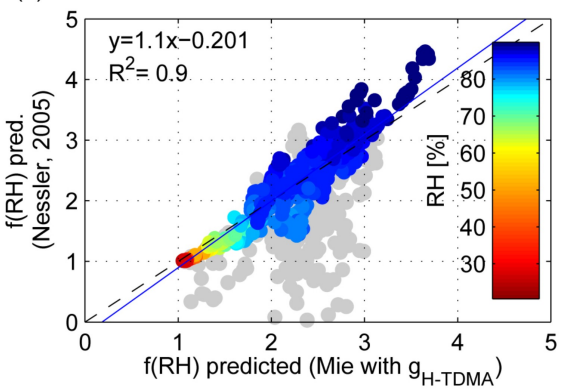

Fig. 4. Comparison of predicted and measured $f(\mathrm{RH})$ (6-min means, entire measured $\mathrm{RH}$ range, SDE excluded). (a) prediction includes size distribution and uses $g$ from the H-TDMA measurements. (b) same as (a) but using $g$ calculated from the AMS/aethalometer data as a proxy for the chemical composition. (c) predicted $f(\mathrm{RH})$ according to Nessler et al. (2005a) vs. measured $f(\mathrm{RH})$. (d) $f(\mathrm{RH})$ predicted according to Nessler et al. (2005a) vs. $f(\mathrm{RH})$ predicted with the method using $g$ of the H-TDMA. The color code represents the RH in the nephelometer, whereas the grey symbols are data points with $\sigma_{\mathrm{sp}}<5 \times 10^{-6} \mathrm{~m}^{-1}$. The blue solid line represents a non-linear least square regression.

H-TDMA (Fig. 4a) and from the AMS/aethalometer data (Fig. 4b). The colors indicate the RH in the nephelometer. All points in grey are $f(\mathrm{RH})$ values from scattering coefficients smaller than the threshold of $5 \times 10^{-6} \mathrm{~m}^{-1}$. They have a high uncertainty and were therefore not used for the linear regression (blue line) and the correlation coefficient. We excluded all data from the time period of the SDE because of missing H-TDMA data.

By using all measured input parameters we get a good agreement between measured and predicted $f(\mathrm{RH})$. However, when $g$ from the AMS/aethalometer is used instead of $g$ from the H-TDMA measurements, the predicted $f(\mathrm{RH})$ is lower than the measured $f(\mathrm{RH})$ at high $\mathrm{RH}$ and higher at low $\mathrm{RH}$. We conclude that we are able to perform a closure of the $f(\mathrm{RH})$ measurements with our model calculations using a combination of SMPS, OPC, AMS, aethalometer and H-TDMA data.

The same correlation plot but with predictions using the approach by Nessler et al. (2005a) is shown in Fig. 4c. The correlation between measurement and prediction is good. At higher RH the Nessler algorithm overestimates $f(\mathrm{RH})$ slightly. As described above, Nessler et al. (2005a) give $90 \% \mathrm{RH}$ as an upper limit. In Fig. $4 \mathrm{~d}$ we compare the prediction using $g$ from the H-TDMA with the model of Nessler. The two models predict similar $f(\mathrm{RH})$ up to about $85 \% \mathrm{RH}$, but at higher RH either the Nessler approach over- estimates $f(\mathrm{RH})$, or the H-TDMA measurements underestimate $f(\mathrm{RH})$ with the assumptions made.

\subsubsection{Sensitivity of $f(\mathbf{R H})$ to size distribution shape and chemical composition}

To investigate the influence of the size distribution and chemical composition on $f(\mathrm{RH})$, we repeated the model predictions by keeping one or both parameters constant. For a constant shape of the size distribution, the monthly mean normalized size distribution was multiplied with the concentration for each data point instead of using the measured size distributions. For a constant chemical composition one mean refractive index and the mean $g$ from the H-TDMA at the diameter of $265 \mathrm{~nm}$ were taken.

For the sensitivity analysis we only considered $f(\mathrm{RH})$ at RH between 80 and $86 \%$ and used hourly means. The $\mathrm{x}$-axes of all four panels of Fig. 5 show the best possible prediction considering measurements of the size distribution, the chemical composition and $g$, which is used as a reference case for the simplified predictions. The marker color represents the RH in the nephelometer and the grey symbols represent $f(\mathrm{RH})$ values with $\sigma_{\mathrm{sp}}$ below the threshold of $5 \times 10^{-6} \mathrm{~m}^{-1}$. Figure 5a shows the model prediction using a constant size distribution on the y-axis, which reproduces the reference prediction within $\pm 8 \%$. This shows that variations of the 

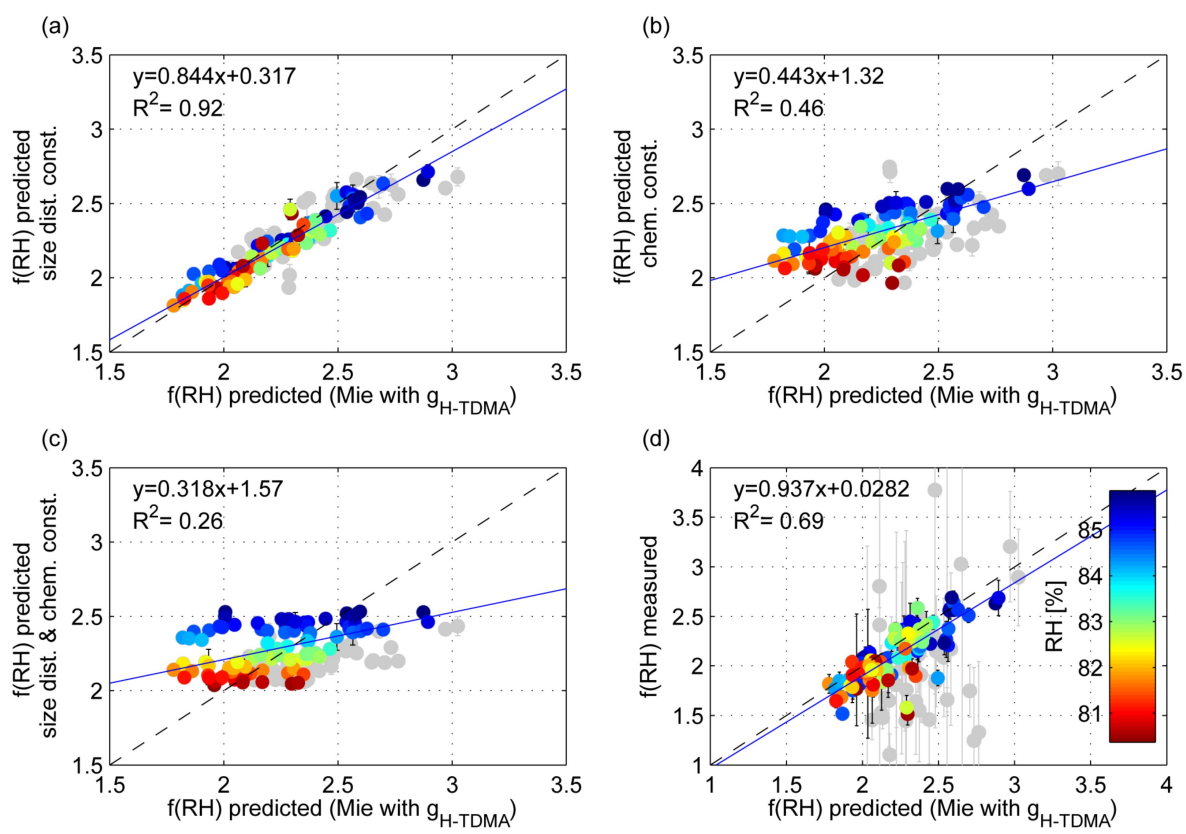

Fig. 5. Sensitivity analysis of $f(\mathrm{RH})$ on the chemical composition and size distribution. Hourly means of different predictions vs. the best possible prediction (using size distribution, chemical composition and hygroscopic growth measurements, excluding the SDE) of $f(\mathrm{RH})$ at $\mathrm{RH}=80-86 \%: f(\mathrm{RH})$ predicted with constant size distribution (a), predicted with constant chemical composition (b), and with combined constant size distribution and constant chemical composition (c). (d) shows measured $f(\mathrm{RH})$ with standard deviation vs. the best possible prediction of $f(\mathrm{RH})$. The color code represents the RH in the nephelometer, whereas the grey symbols are data points with $\sigma_{\mathrm{sp}}<5 \times 10^{-6} \mathrm{~m}^{-1}$. The blue solid line represents a non-linear-least-square regression.

shape of the number size distributions have very little effect on the variability of $f(\mathrm{RH})$ at the Jungfraujoch. A major reason for this is that the shape of the accumulation mode size distribution varies little at the JFJ (Weingartner et al., 1999), which was also true for this time period. Figure $5 \mathrm{~b}$ shows the model prediction using constant mean chemical composition. Neglecting the temporal variability of the chemical composition reduces the correlation to the reference case significantly. This demonstrates that the temporal variability of the chemical composition has some influence on the variability of $f(\mathrm{RH})$. Nevertheless deviations from the reference case remain smaller than a factor of 1.25 , showing that knowing the mean chemical composition is still sufficient for a fair prediction of $f(\mathrm{RH})$ for this month of measurement, always excluding SDE. The model prediction keeping both chemical composition and size distribution constant has the lowest correlation with the reference case, even though absolute deviations remain similar to the previous simplification.

The effects of changing chemical composition become even more important than shown in the above sensitivity analysis, if SDEs are included. Figure 2 clearly shows that $f(\mathrm{RH})$ drops dramatically if the scattering is dominated by non-hygroscopic dust particles. The fact that knowing the mean chemical composition and typical size distribution of the Jungfraujoch aerosol is sufficient for fair predictions of $f(\mathrm{RH})$ explains the good performance of Nessler's approach when comparing predictions with measurements across a wide range of RH (see Fig. 4c), where changes in RH have the dominant influence on $f(\mathrm{RH})$. Furthermore, Nessler's approach is also able to capture SDEs (see Fig. 3d) by inferring the relative contributions of hygroscopic fine mode particles and non-hygroscopic coarse mode dust particles from the Ångström exponent, which is a measure of the average size of the aerosol particle population. In contrast, the other two approaches which use AMS and aethalometer or H-TDMA derived growth factors for prediction of $f(\mathrm{RH})$ are both biased during SDE events because they essentially miss the dust component. The AMS does not measure refractory material such as dust and is limited to the submicron size range. The H-TDMA, which also captures non-hygroscopic dust particles, is limited to particles with diameters below $265 \mathrm{~nm}$. The dominant contribution of dust is found at sizes above $265 \mathrm{~nm}$ and therefore the overall contribution of dust is underestimated also with the H-TDMA approach.

\subsection{RH dependence of derived climate relevant properties}

\subsubsection{RH dependence of the backscatter fraction and the single scattering albedo}

Beside $f(\mathrm{RH})$ other intensive properties depend on $\mathrm{RH}$ : the Ångström exponent $\stackrel{\circ}{s}_{s}$, the backscatter fraction $b$ and the single scattering albedo $\omega_{0}$. In this section we will focus on $b$ 

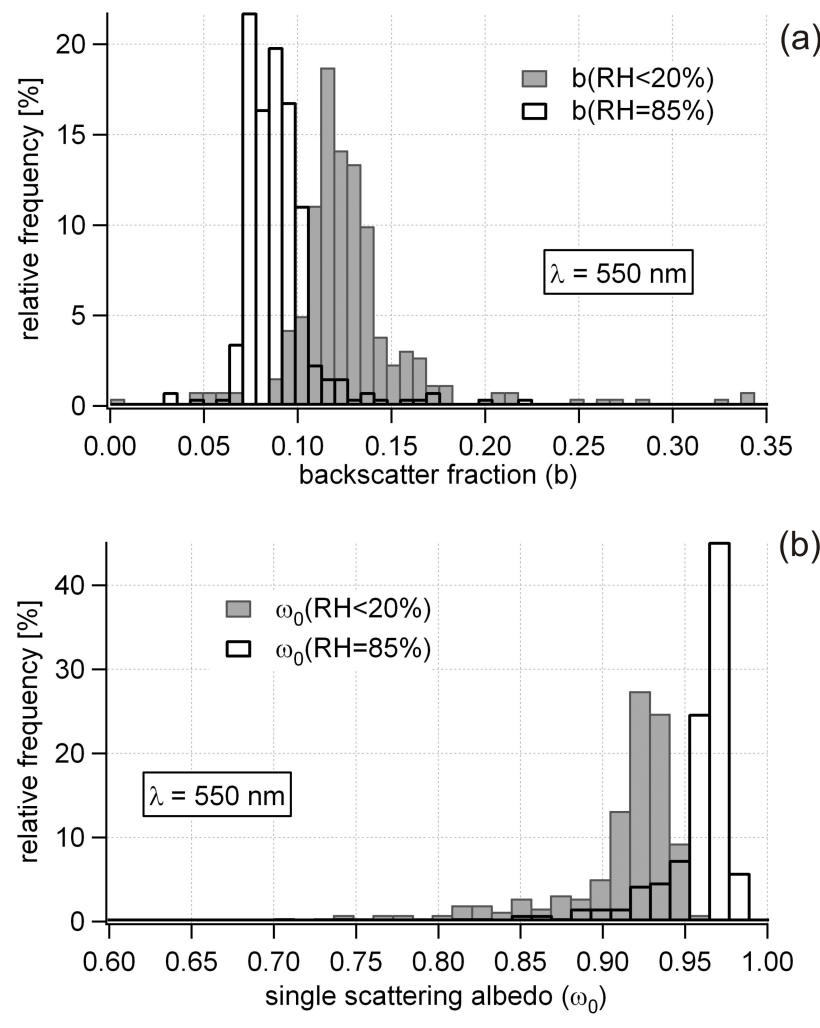

Fig. 6. Frequency distribution (hourly means) of the backscatter fraction $b$ (a) and of the single scattering albedo $\omega_{0}$ (b) at $85 \% \mathrm{RH}$ (white) and below 20\% RH (grey). The Saharan dust event (SDE) at the end of the campaign as well as data points with $\sigma_{\mathrm{sp}}<10^{-6} \mathrm{~m}^{-1}$ were excluded.

and $\omega_{0}$. Figure 6 presents frequency distributions of hourly means of $b$ and $\omega_{0}$ at $550 \mathrm{~nm}$ wavelength from 1 to 26 May, excluding the last three days of the measurement campaign, when the Saharan dust event was present. Data points with $\sigma_{\mathrm{sp}}<10^{-6} \mathrm{~m}^{-1}$ were also omitted.

Figure $6 \mathrm{a}$ displays the relative frequency of $262 \mathrm{~h}$ of measured $b$ at $\mathrm{RH}<20 \%$ and $\mathrm{RH}=85 \%$. The $b(\mathrm{RH}=85 \%)$ originates from $\sigma_{\mathrm{sp}}$ and $\sigma_{\mathrm{bsp}}$ values at RH between 75 and $95 \%$ recalculated to $\mathrm{RH}=85 \%$ using Eq. (5). The $b(\mathrm{RH}<20 \%)$ is between 0.08 and 0.18 for $90 \%$ of the time, with the mode being at 0.115 . The $b(\mathrm{RH}=85 \%)$ is lower (between 0.06 and 0.11 for $90 \%$ of the time), since the aerosol particles are larger and hence scatter more in the forward direction. The mean $b(\mathrm{RH}<20 \%)$ and $b(\mathrm{RH}=85 \%)$ are listed in Table 2.

Figure $6 \mathrm{~b}$ presents the frequency distribution of $\omega_{0}(\mathrm{RH}<20 \%)$ and $\omega_{0}(\mathrm{RH}=85 \%)$. The latter was determined from $\sigma_{\mathrm{sp}}$ values recalculated to $\mathrm{RH}=85 \%$ as described above and dry $\sigma_{\mathrm{ap}}$ values assuming that the absorption does not change with RH (Nessler et al., 2005b). Out of $259 \mathrm{~h}$ of measurement $\omega_{0}(\mathrm{RH}<20 \%)$ was between 0.83 and 0.95 for more than $90 \%$ of the time and between 0.91 and 0.94 for more than $50 \%$ of the time. In contrast, $\omega_{0}(\mathrm{RH}=85 \%)$ was below 0.9 for less than $7 \%$ of the time,

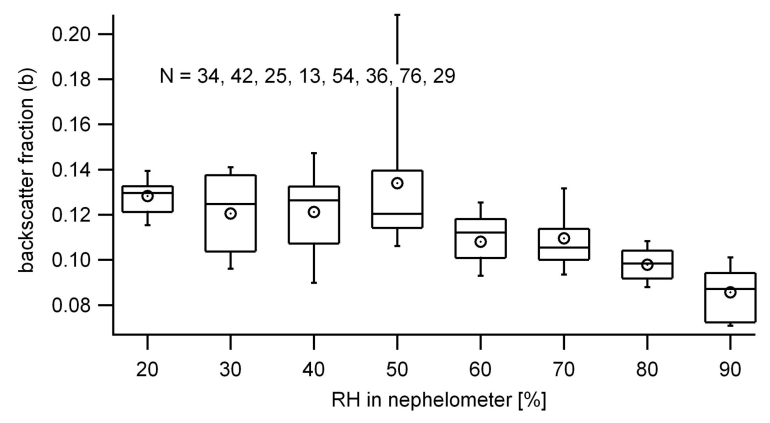

(a)

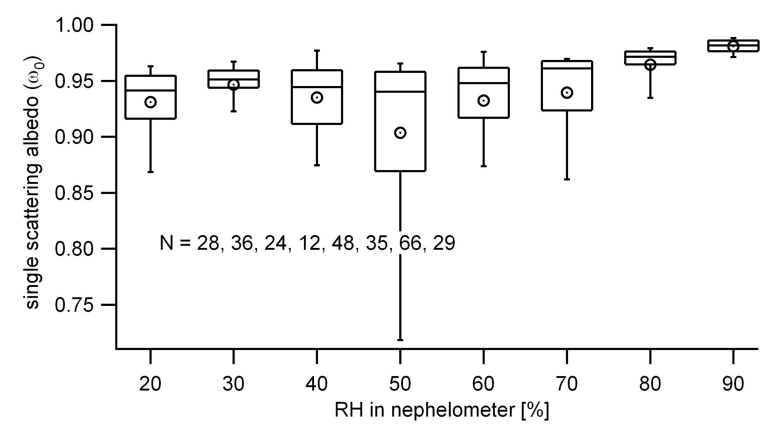

Fig. 7. Box- and whisker-plot of the backscatter fraction (a) and the single scattering albedo (b) sorted in bins with a width of $10 \% \mathrm{RH}$. Every box contains $N 10$-min data, measured within $\pm 5 \%$ of the indicated RH. The circles are the mean values, the horizontal lines in the boxes are the medians, the bottom and top limits of the boxes are the 25 th and 75 th percentiles and the whiskers extend to the 10th and 90 th percentiles.

and between 0.96 and 0.98 for about $50 \%$ of the time. On average $\omega_{0}$ increases by $\sim 0.05$ due to water uptake (see also Table 2).

Since the interest is not only on the two RH ranges shown in Fig. 6, we display box plots of $b$ and $\omega_{0}$ for different RH bins in Fig. 7. Here we present a subset of the whole dataset where humidograms were measured (totally $51 \mathrm{~h}$ of measurements).

The backscatter fraction $b$ decreases with increasing RH from about 0.13 at $20 \pm 5 \% \mathrm{RH}$ to about 0.09 at $90 \pm 5 \% \mathrm{RH}$. The decrease is not perfectly monotonous, but we assume that this is mainly due to the low number of points measured at $50 \%$ RH. $\omega_{0}$ shows the opposite behavior above $50 \% \mathrm{RH}$, it increases with increasing RH. The observed deviation at $50 \% \mathrm{RH}$ is again caused by poor statistics which is based on 12 data points. For both $b(\mathrm{RH}=50 \%)$ and $\omega_{0}(\mathrm{RH}=50 \%)$ a single outlier influences the mean values.

\subsubsection{RH dependence of the radiative forcing}

As $\sigma_{\mathrm{sp}}, \omega_{0}$ and $b$ are all $\mathrm{RH}$ dependent, the radiative forcing $\Delta F$, given by the radiative forcing equation by Haywood and Shine (1995), is also RH dependent: 


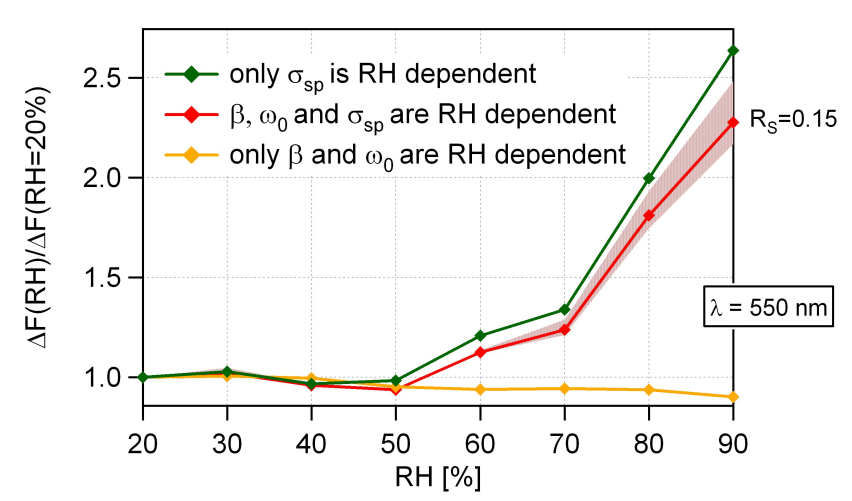

Fig. 8. Ratio of radiative forcing at a certain $\mathrm{RH}$ to radiative forcing at dry conditions $(\mathrm{RH}=20 \%)$ for $R_{S}=0.15$, depending on $\mathrm{RH}$ for three different cases where the RH dependence of the following parameters is considered: only $\sigma_{\mathrm{sp}}$ (green curve), $\sigma_{\mathrm{sp}}, \omega_{0}$ and $\beta$ (red curve), and only $\omega_{0}$ and $\beta$ (yellow curve). The red area shows the $R_{S}$ dependence of the red curve $\left(0.05<R_{S}<0.25\right)$.

$$
\begin{array}{r}
\Delta F(\mathrm{RH}) \approx-D S_{0} T_{\mathrm{atm}}^{2}\left(1-A_{C}\right) \omega_{0}(\mathrm{RH}) \beta(\mathrm{RH}) \delta(\mathrm{RH}) . \\
\cdot\left\{\left(1-R_{S}\right)^{2}-\left(\frac{2 R_{S}}{\beta(\mathrm{RH})}\right)\left[\left(\frac{1}{\omega_{0}(\mathrm{RH})}\right)-1\right]\right\} .
\end{array}
$$

The following parameters in the equation are $\mathrm{RH}$ independent: fractional daylight $D$, solar flux $S_{0}$, atmospheric transmission $T_{\text {atm }}$, fractional cloud amount $A_{C}$, surface reflectance $R_{S}$. The RH dependent upscatter fraction $\beta$ was calculated from the backscatter fraction $b$ with Eq. (3). The spectrally weighted aerosol optical depth $\delta$ depends on $\mathrm{RH}$ via $\sigma_{\text {sp }}$ and $\sigma_{\text {ap }}$. With Eq. (7) $\sigma_{\text {ap }}$ can be displaced in the following way:

$\sigma_{\mathrm{ap}}(\mathrm{RH})=\frac{\sigma_{\mathrm{sp}}(\mathrm{RH})}{\omega_{0}(\mathrm{RH})}-\sigma_{\mathrm{sp}}(\mathrm{RH})$,

which results in an RH dependent aerosol optical depth of:

$\delta=\int \frac{\sigma_{\mathrm{sp}}(\mathrm{RH})}{\omega_{0}(\mathrm{RH})} \mathrm{d} z$.

To investigate the $\mathrm{RH}$ dependence of the radiative forcing $\Delta F$, we calculate $\Delta F(\mathrm{RH}) / \Delta F(\mathrm{RH}=20 \%)$ which is now only dependent on $R_{S}, f(\mathrm{RH}), \omega_{0}$ and $b$ :

$$
\begin{array}{r}
\frac{\Delta F(\mathrm{RH})}{\Delta F(\mathrm{RH}=20 \%)}=\frac{\beta(\mathrm{RH})}{\beta(\mathrm{RH}=20 \%)} f(\mathrm{RH}) . \\
\left\{\frac{\left(1-R_{S}\right)^{2}-\left(\frac{2 R_{S}}{\beta(\mathrm{RH})}\right)\left[\left(\frac{1}{\omega_{0}(\mathrm{RH})}\right)-1\right]}{\left(1-R_{S}\right)^{2}-\left(\frac{2 R_{S}}{\beta(\mathrm{RH}=20 \%)}\right)\left[\left(\frac{1}{\omega_{0}(\mathrm{RH}=20 \%)}\right)-1\right]}\right\} .
\end{array}
$$

$R_{S}$ is taken as 0.15 (global average, Hummel and Reck, 1979) and the RH dependence of $\omega_{0}$ and $b$ is taken from the parameterization presented above (Fig. 7).

Figure 8 clearly shows that the radiative forcing increases for $\mathrm{RH}>50 \%$ and is more than twice as high at $90 \% \mathrm{RH}$ than at $40 \%$ RH. Two effects influence this behavior: first and most important is the RH dependence of $\sigma_{\mathrm{sp}}$, shown as green curve, where $\omega_{0}$ and $b$ are assumed to be RH independent. The total RH dependence of $\Delta F$ gets slightly smaller, when the RH dependence of $\omega_{0}$ and $b$ is taken into account. The reason for this is that $b$ decreases with increasing $\mathrm{RH}$.

To be able to transform the radiative forcing from one $\mathrm{RH}$ to another we studied the red curve of Fig. 8. It tells us that the radiative forcing increases by $24 \%, 19 \%, 14 \%, 11 \%$, if the RH increases from $70 \%$ to $75 \%, 75 \%$ to $80 \%, 80 \%$ to $85 \%$ and $85 \%$ to $90 \%$, respectively.

The radiative forcing due to aerosols does not only depend on the aerosol properties but also on the surface albedo of the ground underneath the aerosol. The last term of Eq. (9) in curly brackets determines whether an aerosol layer above a certain surface leads to cooling or warming (Haywood and Shine, 1995). The sensitivity of the red curve on $R_{S}$ is shown with the red area, which displays the variability of the red curve with $R_{S}$ between 0.25 (upper limit) and 0.05 (lower limit). For the aerosol sampled at the JFJ and so in the free troposphere the critical $R_{S}$, at which this aerosol layer would change from a net cooling to a net warming effect, is at $R_{S}=0.51$ for dry conditions and $R_{S}=0.61$ at $80 \% \mathrm{RH}$. Surface reflectance of this level would be found above snow and ice.

\section{Summary and conclusions}

During a month-long measurement campaign at the high alpine site Jungfraujoch we measured light scattering enhancement factors $f(\mathrm{RH})$ at different $\mathrm{RH}$, but mostly between 80 and $90 \%$ RH. $f(\mathrm{RH}=85 \%)$ reached values up to 3.3 , whereas the lowest $f(\mathrm{RH}=85 \%)$ values of 1.2 were detected during a Saharan dust event (SDE). The mean $f(\mathrm{RH}=85 \%)$ of the measured free tropospheric aerosol (2.23) is higher than the $f(\mathrm{RH}=82 \%)$ of polluted and clean aerosol in Europe during ACE-2 (1.46 and 1.69, Carrico et al., 2000), but lower than marine aerosol (2.42 at $82 \%$ $\mathrm{RH}$, Carrico et al., 2003) or polluted aerosol of East Asia $(f(\mathrm{RH}=85 \%)=2.75$, Kim et al., 2006). At the JFJ the $\mathrm{RH}$ dependence of $f(\mathrm{RH})$ was similar on three different days, excluding the SDE event, indicating that on these days the aerosol had similar physical and chemical properties in the relevant size range.

Measured $f(\mathrm{RH})$ were compared to predictions obtained with two different model approaches: the first model uses Mie theory with measured size distributions, chemical composition and a hygroscopicity parameter to calculate $f(\mathrm{RH})$. The hygroscopicity parameter $g$ can be calculated from measurements of the chemical composition by the AMS and the aethalometer or direct measurements from the H-TDMA. The second simplified approach is based on the model of Nessler et al. (2005a), which uses Mie theory and the measured Ångström exponent of the dry scattering coefficient to 
calculate $f(\mathrm{RH})$. Both models reproduce $f(\mathrm{RH})$ quite well. The Nessler model works fine up to RH values of $85 \%$, whereas at higher $\mathrm{RH}$ it overestimates $f(\mathrm{RH})$. It also predicts $f(\mathrm{RH})$ quite well during the SDE. The first model has constraints during the SDE: The AMS does not measure refractory material such as dust and it is limited to the submicron size range. The H-TDMA, which also captures nonhygroscopic dust particles, is limited to particles with diameters below $265 \mathrm{~nm}$. With the first model we additionally performed a sensitivity analysis on the input parameters (chemical composition and size distribution). We found that the variability of the chemical composition has a dominant influence of the variability of $f(\mathrm{RH})$, but also a mean size distribution is required to predict $f(\mathrm{RH})$ well.

The RH influences also other intensive properties than $f(\mathrm{RH})$ : the backscatter fraction $b$ and the single scattering albedo $\omega_{0} . b$ gets smaller with increasing RH, due to particle growth and $\omega_{0}$ gets closer to 1 with increasing $\mathrm{RH}$, because the influence of the scattering upon the absorption gets more important. By combining all three investigated RH dependent variables $\omega_{0}, b$ and $f(\mathrm{RH})$ we can estimate the $\mathrm{RH}$ dependence of the radiative forcing due to aerosols. At $90 \% \mathrm{RH}$ the radiative forcing is 2.3 times higher than at $20 \% \mathrm{RH}$ for the conditions found at the JFJ in May 2008.

Acknowledgements. We thank the International Foundation High Altitude Research Stations Jungfraujoch and Gornergrat (HFSJG), which made it possible to carry out the experiments at the High Altitude Research Station at the Jungfraujoch. Financial support for this work was received from the EC projects EUSAAR (European Supersites for Atmospheric Aerosol Research), GEOMON (Global Earth Observation and Monitoring) and EUCAARI (European Integrated Project on Aerosol Cloud Climate Air Quality Interactions), as well as from MeteoSwiss in the framework of the Global Atmosphere Watch program and the Swiss National Science Foundation (grant PZ00P2 121911/1). NILU is acknowledged for providing the FLEXTRA trajectories (www.nilu.no/trajectories) used in this study.

Edited by: W. Birmili

\section{References}

Alfarra, M. R., Paulsen, D., Gysel, M., Garforth, A. A., Dommen, J., Prévôt, A. S. H., Worsnop, D. R., Baltensperger, U., and Coe, H.: A mass spectrometric study of secondary organic aerosols formed from the photooxidation of anthropogenic and biogenic precursors in a reaction chamber, Atmos. Chem. Phys., 6, 52795293, 2006,

http://www.atmos-chem-phys.net/6/5279/2006/.

Anderson, T. L. and Ogren, J. A.: Determining aerosol radiative properties using the TSI 3563 integrating nephelometer, Aerosol Sci. Tech., 29, 57-69, 1998.

Baltensperger, U., Gäggeler, H. W., Jost, D. T., Emmenegger, M., and Nägeli, W.: Continuous background aerosol monitoring with the epiphaniometer, Atmos. Environ., 25A(3/4), 629-634, 1991.
Baltensperger, U., Gäggeler, H. W., Jost, D. T., Lugauer, M., Schwikowski, M., Weingartner, E., and Seibert, P.: Aerosol climatology at the high-alpine site Jungfraujoch, Switzerland, J. Geophys. Res., 102(D16), 19707-19715, 1997.

Baltensperger, U., Schwikowski, M., Jost, D. T., Nyeki, S., Gäggeler, H. W., and Poulidas, O.: Scavenging of the atmospheric constituents in mixed phase clouds at the high-alpine site Jungfraujoch Part I: Basic concept and aerosol scavenging by clouds, Atmos. Environ., 32(23), 3975-3983, 1998.

Bohren, C. and Huffmann, D.: Absorption and Scattering of Light by Small Particles, Wiley-VCH, New York, USA, 2004.

Canagaratna, M. R., Jayne, J. T., Jimenez, J. L., Allan, J. D., Alfarra, M. R., Zhang, Q., Onasch, T. B., Drewnick, F., Coe, H., Middlebrook, A., Delia, A., Williams, L. R., Trimborn, A. M., Northway, M. J., DeCarlo, P. F., Kolb, C. E., Davidovits, P., and Worsnop, D. R.: Chemical and microphysical characterization of ambient aerosols with the Aerodyne aerosol mass spectrometer, Mass Spectrom. Rev., 26(2), 185-222, 2007.

Carrico, C. M., Rood, M. J., and Ogren, J. A.: Aerosol light scattering properties at Cape Grim, Tasmania, during the First Aerosol Characterization Experiment (ACE 1), J. Geophys. Res., 103, 16565-16574, 1998.

Carrico, C. M., Rood, M. J., Ogren, J. A., Neusüss, C., Wiedensohler, A., and Heintzenberg, J.: Aerosol optical properties at Sagres, Portugal during ACE-2, Tellus, 52B, 694-715, 2000.

Carrico, C. M., Kus, P., Rood, M. J., Quinn, P. K., and Bates, T. S.: Mixtures of pollution, dust, sea salt, and volcanic aerosol during ACE-Asia: Radiative properties as a function of relative humidity, J. Geophys. Res., 108(D23), 8650, doi:10.1029/2003JD003405, 2003.

Charlson, R. J., Schwartz, S. E., Hales, J. M., Cess, R. D., Coakley, J. A., Jr., Hansen, J. E., and Hofmann, D. J.: Climate forcing by anthropogenic aerosols, Science, 255, 423-430, 1992.

Collaud Coen, M., Weingartner, E., Schaub, D., Hueglin, C., Corrigan, C., Henning, S., Schwikowski, M., and Baltensperger, U.: Saharan dust events at the Jungfraujoch: detection by wavelength dependence of the single scattering albedo and first climatology analysis, Atmos. Chem. Phys., 4, 2465-2480, 2004, http://www.atmos-chem-phys.net/4/2465/2004/.

Collaud Coen, M., Weingartner, E., Nyeki, S., Cozic, J., Henning, S., Verheggen, B., Gehrig, R., and Baltensperger, U.: Long-term trend analysis of aerosol variables at the highalpine site Jungfraujoch, J. Geophys. Res., 112, D13213, doi:10.1029/2006JD007995, 2007.

Collaud Coen, M., Weingartner, E., Apituley, A., Ceburnis, D., Flentje, H., Henzing, J. S., Jennings, S. G., Moerman, M., Petzold, A., Schmidhauser, R., Schmid, O., and Baltensperger, U.: Minimizing light absorption measurement artifacts of the Aethalometer: evaluation of five correction algorithms, Atmos. Meas. Tech. Discuss., 2, 1725-1770, 2009, http://www.atmos-meas-tech-discuss.net/2/1725/2009/.

Cozic, J., Verheggen, B., Weingartner, E., Crosier, J., Bower, K. N., Flynn, M., Coe, H., Henning, S., Steinbacher, M., Henne, S., Collaud Coen, M., Petzold, A., and Baltensperger, U.: Chemical composition of free tropospheric aerosol for $\mathrm{PM}_{1}$ and coarse mode at the high alpine site Jungfraujoch, Atmos. Chem. Phys., 8, 407-423, 2008,

http://www.atmos-chem-phys.net/8/407/2008/.

Day, D. E. and Malm, W. C.: Aerosol light scattering measure- 
ments as a function of relative humidity: A comparison between measurements made at three different sites, Atmos. Environ., 35, 5169-5176, 2001.

DeCarlo, P. F., Kimmel, J. R., Trimborn, A., Northway, M. J., Jayne, J. T., Aiken, A. C., Gonin, M., Fuhrer, K., Horvath, T., Docherty, K. S., Worsnop, D. R., and Jimenez, J. L.: Fielddeployable, high-resolution, time-of-flight aerosol mass spectrometer, Anal. Chem., 78(24), 8281-8289, 2006.

Dinar, E., Mentel, T. F., and Rudich, Y.: The density of humic acids and humic like substances (HULIS) from fresh and aged wood burning and pollution aerosol particles, Atmos. Chem. Phys., 6, 5213-5224, 2006,

http://www.atmos-chem-phys.net/6/5213/2006/.

Fierz-Schmidhauser, R., Zieger, P., Wehrle, G., Jefferson, A., Ogren, J. A., Baltensperger, U., and Weingartner, E.: Measurement of relative humidity dependent light scattering of aerosols, Atmos. Meas. Tech., 3, 39-50, 2010, http://www.atmos-meas-tech.net/3/39/2010/.

Gosse, S. F., Wang, M., Labrie, D., and Chylek, P.: Imaginary part of the refractive index of sulfates and nitrates in the 0.7-2.6- $\mu \mathrm{m}$ spectral region, Appl. Optics, 36(16), 3622-3634, 1997.

Gysel, M., McFiggans, G. B., and Coe, H.: Inversion of tandem differential mobility analyser (TDMA) measurements, J. Aerosol Sci., 40, 134-151, 2009.

Hale, G. M. and Querry, M. R.: Optical constants of water in the $200-\mathrm{nm}$ to $200-\mu \mathrm{m}$ wavelength region, Appl. Optics, 12, 3, 555$563,1973$.

Haywood, J. M. and Shine, K. P.: The effect of anthropogenic sulfate and soot aerosol on the clear sky planetary radiation budget, Geophys. Res. Lett., 22(5), 603-606, 1995.

Hess, M., Koepke, P., and Schult, I.: Optical properties of aerosols and clouds: The software package OPAC, B. Am. Meteorol. Soc., 79(5), 831-844, 1998.

Hummel, J. R. and Reck, R. A.: A global surface model, J. Appl. Meteorol., 18(3), 239-253, 1979.

IPCC: Climate Change 2007 - The Physical Science Basis, edited by: Solomon, S., Cambridge University Press, New York, 2007.

Kim, J., Yoon, S.-C., Jefferson, A., and Kim, S.-W.: Aerosol hygroscopic properties during Asian dust, pollution, and biomass burning episodes at Gosan, Korea in April 2001, Atmos. Environ., 40, 1550-1560, 2006.

Koloutsou-Vakakis, S., Carrico, C. M., Kus, P., Rood, M. J., Li, Z., and Shrestha, R.: Aerosol properties at a midlatitude Northern Hemisphere continental site, J. Geophys. Res., 106(D3), 30193032, 2001.

Kotchenruther, R. A. and Hobbs, P. V.: Humidification factors of aerosols from biomass burning in Brazil, J. Geophys. Res., 103(D24), 32081-32089, 1998.

Li-Jones, X., Maring, H. B., and Prospero, J. M.: Effect of relative humidity on light scattering by mineral dust aerosol as measured in the marine boundary layer over the tropical Atlantic Ocean, J. Geophys. Res., 103(D23), 31113-31121, 1998.

Li, J., Wong, J. G. D., Dobbie, J. S., and Chylek, P.: Parameterization of the optical properties of sulfate aerosols, J. Atmos. Sci., 58(2), 193-209, 2001.

Lide, D. R.: Handbook of Chemistry and Physics, 89th (Internet Version 2009), CRC Press/Taylor and Francis, Boca Raon, Fl, 2008.

Lugauer, M., Baltensperger, U., Furger, M., Gäggeler, H. W.,
Jost, D. T., Schwikowski, M., and Wanner, H.: Aerosol transport to the high Alpine sites Jungfraujoch (3454 m asl) and Colle Gnifetti (4452 m asl), Tellus, 50B, 76-92, 1998.

Mie, G.: Beiträge zur Optik trüber Medien, speziell kolloidaler Metalllösungen, Ann. Phys., 25(4), 377-445, 1908.

Nessler, R., Weingartner, E., and Baltensperger, U.: Adaptation of dry nephelometer measurements to ambient conditions at the Jungfraujoch, Environ. Sci. Technol., 39, 2219-2228, 2005a.

Nessler, R., Weingartner, E., and Baltensperger, U.: Effect of humidity on aerosol light absorption and its implications for extinction and the single scattering albedo illustrated for a site in the lower free troposphere, J. Aerosol Sci., 36, 958-972, 2005b.

Nyeki, S., Baltensperger, U., Colbeck, I., Jost, D. T., Weingartner, E., and Gäggeler, H. W.: The Jungfraujoch high-alpine research station $(3454 \mathrm{~m})$ as a background clean continental site for the measurement of aerosol parameters, J. Geophys. Res., 103(D6), 6097-6107, 1998.

Palmer, K. F. and Williams, D.: Optical constants of sulfuric acid; application to the clouds of Venus?, Appl. Optics, 14(1), 208219, 1975.

Petters, M. D. and Kreidenweis, S. M.: A single parameter representation of hygroscopic growth and cloud condensation nucleus activity, Atmos. Chem. Phys., 7, 1961-1971, 2007, http://www.atmos-chem-phys.net/7/1961/2007/.

Schwartz, S. E.: The whitehouse effect - shortwave radiative forcing of climate by anthropogenic aerosols: An overview, J. Aerosol Sci., 27, 359-382, 1996.

Schwikowski, M., Seibert, P., Baltensperger, U., and Gäggeler, H. W.: A study of an outstanding Saharan dust event at the high-alpine site Jungfraujoch, Switzerland, Atmos. Environ., 29(15), 1829-1842, 1995.

Sheridan, P. J. and Ogren, J. A.: Observation of the vertical and regional variability of aerosol optical properties over central and eastern North America, J. Geophys. Res., 104(D14), 1679316805, 1999.

Sheridan, P. J., Delene, D. J., and Ogren, J. A.: Four years of continuous surface aerosol measurements from the Department of Energy's Atmospheric Radiation Program Southern Great Plains Cloud and Radiation Testbed site, J. Geophys. Res., 106, 2073520747, 2001.

Sjogren, S., Gysel, M., Weingartner, E., Alfarra, M. R., Duplissy, J., Cozic, J., Crosier, J., Coe, H., and Baltensperger, U.: Hygroscopicity of the submicrometer aerosol at the high-alpine site Jungfraujoch, $3580 \mathrm{~m}$ a.s.l., Switzerland, Atmos. Chem. Phys., 8, 5715-5729, 2008, http://www.atmos-chem-phys.net/8/5715/2008/.

Stokes, R. H. and Robinson, R. A.: Interactions in aqueous nonelectrolyte solutions, I. Solute-solvent equilibria, J. Phys. Chem., 70, 2126-2130, 1966.

Tang, I. N.: Chemical and size effects of hygroscopic aerosols on light scattering coefficients, J. Geophys. Res., 101, 1924519250, 1996.

Toon, O. B., Pollack, J. B., and Khare, B. N.: The optical constants of several atmospheric aerosol species: Ammonium sulfate, aluminium oxide, and sodium chloride, J. Geophys. Res.-Oc. Atm., 81(33), 5733-5748, 1976.

Topping, D. O., McFiggans, G. B., and Coe, H.: A curved multicomponent aerosol hygroscopicity model framework: Part 2 Including organic compounds, Atmos. Chem. Phys., 5, 1223- 
1242, 2005,

http://www.atmos-chem-phys.net/5/1223/2005/.

Wang, W., Rood, M. J., Carrico, C. M., Covert, D. S., Quinn, P. K., and Bates, T. S.: Aerosol optical properties along the northeast coast of North America during the New England Air Quality Study - Intercontinental Transport and Chemical Transformation 2004 campaign and the influence of aerosol composition, J. Geophys. Res., 112, D10S23, doi:10.1029/2006JD007579, 2007.

Weingartner, E., Nyeki, S., and Baltensperger, U.: Seasonal and diurnal variation of aerosol size distributions $(10<D<750 \mathrm{~nm})$ at a high-alpine site (Jungfraujoch $3580 \mathrm{~m}$ asl), J. Geophys. Res., 104(D21), 26809-26820, 1999.

Weingartner, E., Gysel, M., and Baltensperger, U.: Hygroscopicity of aerosol particles at low temperatures, 1 . New low-temperature H-TDMA instrument: Setup and first applications, Environ. Sci. Technol., 36, 55-62, 2002.
Weingartner, E., Saathoff, H., Schnaiter, M., Streit, N., Bitnar, B., and Baltensperger, U.: Absorption of light by soot particles: Determination of the absorption coefficient by means of aethalometers, J. Aerosol Sci., 34, 1445-1465, 2003.

Wiscombe, W. J. and Grams, G. W.: The backscattered fraction in two-stream approximations, J. Atmos. Sci., 33, 2440-2451, 1976.

WMO/GAW: Aerosol Measurement Procedures Guidelines and Recommendations, World Meteorological Organization Global Atmosphere Watch, Geneva, Switzerland, 2003.

Yan, P., Pan, X. L., Tang, J., Zhou, X. J., Zhang, R. J., and Zeng, L. M.: Hygroscopic growth of aerosol scattering coefficient: A comparative analysis between urban and suburban sites at winter in Beijing, Particuology, 7, 52-60, 2009. 